\title{
The volumetric stability, chloride binding capacity and stability of the Portland cement-GBFS pastes: An approach from the viewpoint of hydration products
}

\author{
Tongsheng Zhang ${ }^{\mathrm{a}, \mathrm{d}}$, Wenli Tiana, Yiqun Guo ${ }^{\mathrm{a}}$, Anna Bogush ${ }^{\mathrm{b}}$, Elena Khayrulina ${ }^{\mathrm{c}}$, Jiangxiong \\ Wei ${ }^{\mathrm{a}, \mathrm{d}}$, Qijun $\mathrm{Yu}^{\mathrm{a}, \mathrm{d}^{*}}$ \\ ${ }^{a}$ School of Materials Science and Engineering, South China University of Technology, 510640 Guangzhou, China \\ ${ }^{b}$ Department of Earth Sciences, University College London, WC1E 6BT London, UK \\ ${ }^{\mathrm{c}}$ Institute of Natural Science, Perm State National Research University, 614990 Perm, Russia \\ ${ }^{\mathrm{d}}$ Guangdong Low Carbon Technologies Engineering Center for Building Materials, 510640 Guangzhou, China
}

Abstract: An optimization of Portland cement (PC)-supplementary cementitious materials (SCMs) system focusing on the characteristics of hydration products is significantly important to decrease the thermal and chemical shrinkages and increase the chloride binding capacity, consequently to decline the diffusion rate of chloride into cement-based materials. In the present study, ultrafine granulated blast furnace slag (GBFS) was added into ultrafine Portland cement (PC) pastes to obtain homogenous hydration products, and then the hydration heat, chemical shrinkage, chloride binding capacity and stability of the PC-GBFS pastes were investigated. The results show that with the increase of the GBFS addition, the ultimate hydration heat of the PC-GBFS pastes increased initially and then decreased sharply, and the chemical shrinkage increased slightly with the increase of the GBFS addition. The cement pastes with 40-60\% GBFS had acceptable hydration heat and chemical shrinkage, more important, its total bound chloride and non-water-soluble bound chloride increased by $24 \%$ and $177 \%$, respectively, compared to those of Portland cement paste. Additionally, about 50\% of chemically bound chloride in the form of Friedel's salt was water-soluble chloride due to ion-exchang, and 5-20\% of physically bound chloride in C-S-H was non-water-soluble chloride after desorption.

Key words: Chemically bound chloride; Physically bound chloride; Chloride binding stability; Friedel's salt; Chemical shrinkage

\section{Introduction}

Chloride-induced corrosion is regarded as the key factor influencing the durability of reinforced concrete structures exposed to chloride-rich environment, such as marine, salt lake, and salt mine areas.

When the concentration of chloride surrounded the steel bar exceeds the threshold, the stable passive

* Corresponding author. E-mail address: concyuq@scut.edu.cn (Qijun Yu). Tel./fax.: +86-020-87114233. 
layer on the steel surface is partly disrupted followed by accelerated corrosion, and the expansion due to corrosion products finally results in the cracking and spalling of the concrete cover [1]. On the one hand, the porous nature of cement paste, in terms of cracks and connected pore-network, provides migration channels for external chlorides. On the other hand, a certain proportion of chlorides penetrated into cement-based materials can be captured by the hydration products [2,3].

Early age or plastic cracking has been increasingly reported especially for cement-based materials with low water to binder (W/B) ratio [4]. Since concrete is generally well cured at early age, cracks due to moisture evaporation can be minimized. Therefore, cracks in cement-based materials are mainly attributed to thermal shrinkage dominated by hydration heat and chemical shrinkage depended on the density of hydration products [5,6], which are closely related to the characteristics of final hydration products. For Portland cement (PC), the hydration heat generally relates to its fineness, and the chemical shrinkage can be estimated by Paulini equation [7,8], as the composition of hydration products varies slightly, e.g. the composition of C-S-H phase is assigned as $\mathrm{C}_{1.7} \mathrm{SH}_{4}$ at early age of hydration [9]. However, due to significant differences in the hydraulic activity, fineness, chemical and mineral compositions of supplementary cementitious materials (SCMs), the characteristics of hydration products in PC-SCMs pastes vary dramatically, thus it is difficult to estimate the hydration heat and chemical shrinkage. For example, the addition of granulated blast furnace slag (GBFS) with specific surface area $<400 \mathrm{~m}^{2} / \mathrm{kg}$ reduces the hydration heat and chemical shrinkage, while opposite trend is observed when 
incorporating GBFS with specific surface area $>400 \mathrm{~m}^{2} / \mathrm{kg}$, and the ultimate hydration heat and chemical shrinkage also largely depend on the addition of GBFS $[10,11]$.

Chloride can be bound chemically by the calcium aluminate monosulfate (AFm phase, $\mathrm{Al}_{2} \mathrm{O}_{3}-\mathrm{Fe}_{2} \mathrm{O}_{3}$ mono) to form Friedel's salt $\left(\mathrm{C}_{3} \mathrm{~A} \cdot \mathrm{CaCl}_{2} \cdot 10 \mathrm{H}_{2} \mathrm{O}\right)$ or adsorbed physically by $\mathrm{C}-\mathrm{S}-\mathrm{H}$ gel due to its large specific surface area and electrical double layer [2,12]. Notably, the bound chloride can release into pore solution when the chloride concentration of external environment is decreased [13], that is to say, the bound chloride is not stable or the chloride binding capacity is declined. The bound chloride can be further classified into water-soluble and non-water-soluble chlorides, the former can also be diffusible at a low chloride concentration environment, whereas the latter is solidified firmly and has no contribution to the chloride migration. SCMs with high Al content, typically GBFS, are used to increase the chloride binding capacity. Many researchers reported that more $\mathrm{Al}$ available increases the amount of $\mathrm{AFm}$, results in a higher Friedel's salt content $[14,15]$. Whereas others argued that the $\mathrm{Al}^{3+}$ released from GBFS is substituted for $\mathrm{Si}^{4+}$ in C-S-H gel, the C-A-S-H gel formed can adsorb more chloride due to the increased charge density $[13,16]$. Thus, the chloride binding mechanism is still not clarified yet.

Depending on the addition, fineness, chemical composition of GBFS, the type and composition of hydration products surrounding clinker and GBFS particles present significant differences. For instance, the proportion of $\mathrm{C}-\mathrm{S}-\mathrm{H}$ gel increases and the crystal phases (such as, $\mathrm{CH}, \mathrm{AFt}, \mathrm{AFm}$ ) decrease gradually with the increase of the hydration degree and the addition of GBFS [17]. Furthermore, the Ca/Si molar ratio of C-S-H gel decreases from about 1.7 to 0.8 , the $\mathrm{Al} / \mathrm{Si}$ molar ratio of $\mathrm{C}-\mathrm{S}-\mathrm{H}$ gel increases from 
0.08 to 0.25 [9], and the density of C-S-H also increases from $2.25 \mathrm{~g} / \mathrm{cm}^{3}$ to $2.85 \mathrm{~g} / \mathrm{cm}^{3}[18,19]$, which

results in a larger shrinkage and higher cracking potential. Therefore, optimizing the characteristics of hydration products of PC-SCMs system is significantly important to decrease the thermal and chemical shrinkages and increase the chloride binding capacity, consequently to decline the diffusion rate of chloride into cement-based materials.

In the present study, ultrafine GBFS was added into ultrafine Portland cement pastes to obtain homogenous hydration products and minimize the influence of un-hydrated particles. The hydration heat, chemical shrinkage, and chloride binding capacity of PC-GBFS pastes were followed, and special focuses were paid on the stability of chlorides bound in C-S-H gel and Friedel's salt by involving desorption test. The desirable characteristics of the hydration products to reduce the hydration heat and chemical shrinkage, and to improve the chloride binding capacity were defined. The results will be beneficial to the mixture design of cementitious materials from the viewpoint of hydration products, and consequently to improve chloride resistance and durability of cement-based materials that are very important in the chloride-rich environment.

\section{Materials and testing methods}

\subsection{Materials}

The ultrafine GBFS and PC used in the present study were obtained by employing a laboratory air classifier, their chemical compositions, BET specific surface area, and specific density are listed in Table 1, and the Bogue mineral composition of PC is given in Table 2. As shown in Fig. 1, the GBFS and PC 
had similar particle size distribution and more than $80 \%$ of particles laid in the range of 1.0-5.0 $\mu \mathrm{m}$.

Therefore, it is expected that more GBFS and PC particles could be hydrated after 28 days curing [20,21].
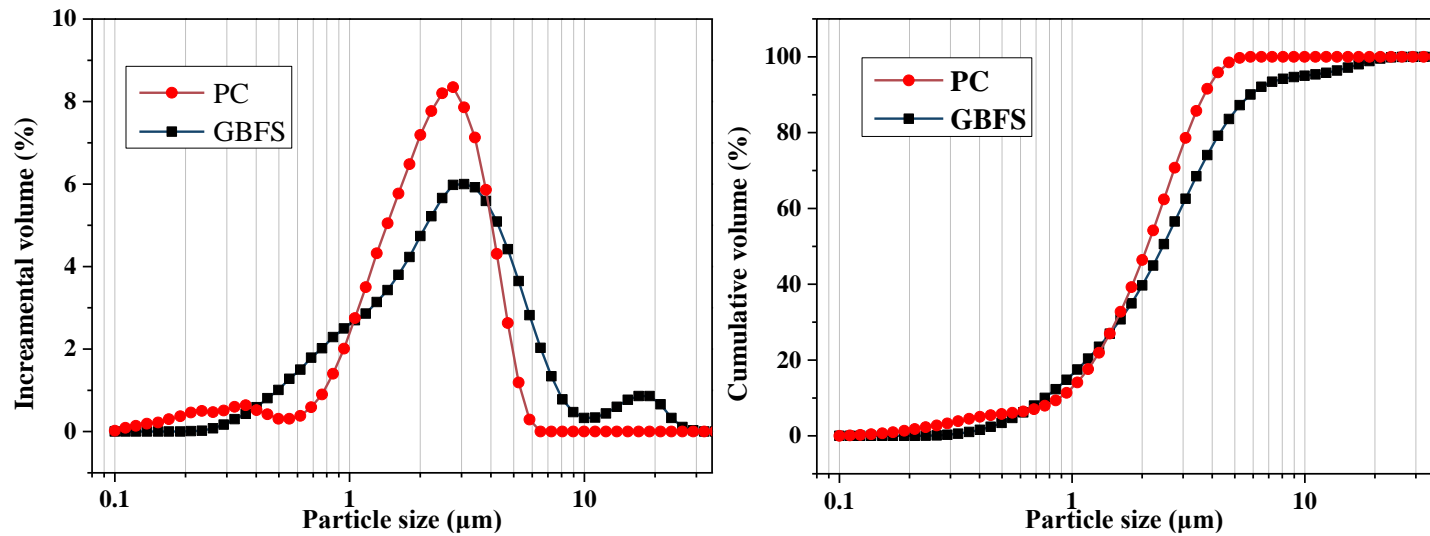

Fig. 1. The particle size distributions of PC and GBFS used in the present study.

Table 1. Chemical composition, BET specific surface area, and specific density of PC and GBFS used in the present study $(\mathrm{wt} \%)$

\begin{tabular}{ccc}
\hline Material & PC & GBFS \\
\hline $\mathrm{SiO}_{2}$ & 19.20 & 34.98 \\
$\mathrm{Al}_{2} \mathrm{O}_{3}$ & 4.20 & 12.00 \\
$\mathrm{Fe}_{2} \mathrm{O}_{3}$ & 2.77 & 0.24 \\
$\mathrm{CaO}$ & 61.60 & 36.54 \\
$\mathrm{MgO}$ & 1.84 & 11.42 \\
$\mathrm{~K}_{2} \mathrm{O}$ & 0.91 & 0.51 \\
$\mathrm{Na}_{2} \mathrm{O}$ & 0.15 & 0.25 \\
$\mathrm{SO}_{3}$ & 4.41 & 0.66 \\
$\mathrm{LOI}$ & 3.23 & 1.48 \\
Others & 1.69 & 1.37 \\
\hline BET specific surface area $\left(\mathrm{m}^{2} / \mathrm{g}\right)$ & 7.05 & 6.08 \\
Specific density $\left(\mathrm{g} / \mathrm{cm}^{3}\right)$ & 3.11 & 2.84 \\
\hline
\end{tabular}

Note: LOI represents loss on ignition.

Table 2. Mineral composition of PC used in the present study (wt $\%$ )

\begin{tabular}{cccccc}
\hline $\mathrm{C}_{3} \mathrm{~S}$ & $\mathrm{C}_{2} \mathrm{~S}$ & $\mathrm{C}_{3} \mathrm{~A}$ & $\mathrm{C}_{4} \mathrm{AF}$ & $\mathrm{CaSO}_{4}$ & Others \\
\hline 59.99 & 9.87 & 6.45 & 8.42 & 7.50 & 7.77 \\
\hline
\end{tabular}

Note: Others includes free-CaO, alkali sulfates, and amorphous phase.

\subsection{Sample preparation}

The PC-GBFS pastes were prepared by mixing cementitious materials and deionized water homogeneously according to the mix proportions listed in Table 3, and the water-to-binder mass ratio (W/B) was kept as 0.50. To simulate the hydration of GBFS in Portland cement paste, a reference GBFS paste was prepared by $90 \%$ GBFS and $10 \% \mathrm{CaO}$ using $0.2 \mathrm{~mol} / \mathrm{L} \mathrm{NaOH}$ solution (seen as simulated pore 
solution [22,23]). The fresh pastes were cast into $20 \mathrm{~mm} \times 20 \mathrm{~mm} \times 20 \mathrm{~mm}$ molds and then cured at $20 \pm 1$

${ }^{\circ} \mathrm{C}$ and $90 \%$ relative humidity (RH) chamber for $24 \mathrm{~h}$, the specimens were demoulded and cured in lime-

saturated water at $20 \pm 1^{\circ} \mathrm{C}$. After 27 days curing, the specimens were crashed into small pieces (about 0.9 4.0 $\mathrm{mm}$ ) and then submerged in liquid nitrogen to terminate their hydration followed by freezedrying. The dried samples were immediately placed in a $11 \% \mathrm{RH}$ chamber with soda lime to minimize carbonation [13].

Table 3. Mix proportions of the PC-GBFS pastes

\begin{tabular}{|c|c|c|c|c|}
\hline \multirow{2}{*}{ Sample ID } & \multicolumn{3}{|c|}{ Proportion (wt.\%) } & \multirow{2}{*}{$\mathrm{W} / \mathrm{B}$} \\
\hline & Portland cement & GBFS & $\mathrm{CaO}$ & \\
\hline G0 & 100 & - & - & \\
\hline $\mathrm{G} 2$ & 80 & 20 & - & \\
\hline G4 & 60 & 40 & - & 0.5 (Deionized water) \\
\hline G6 & 40 & 60 & - & \\
\hline G8 & 20 & 80 & - & \\
\hline G9 & 0 & 90 & 10 & $0.5(0.2 \mathrm{~mol} / \mathrm{L} \mathrm{NaOH}$ solution $)$ \\
\hline
\end{tabular}

\subsection{Testing methods}

\subsubsection{Heat evolution measurement}

The heat evolution of the PC-GBFS pastes with a W/B of 0.5 was followed at $25^{\circ} \mathrm{C}$ using a TAM-

Air isothermal calorimeter according to ASTM C 1702-09 [24].

\subsubsection{Chemical shrinkage measurement}

The chemical shrinkage of the PC-GBFS binder was measured by volumetric method at $20 \pm 1^{\circ} \mathrm{C}$. The testing procedures used were improved from ASTM C 1608 [25] by adding a magnetic stirring bar to avoid generation of internal pores, and the details were specified in the literature [26].

\subsubsection{Chloride binding and desorption measurements}


About $20 \mathrm{~g}$ freeze-dried hydrated cement paste was placed in a plastic tube containing $40 \mathrm{~mL}$ of

$\mathrm{Ca}(\mathrm{OH})_{2}$ saturated- $\mathrm{NaCl}$ solution. The concentrations of $\mathrm{NaCl}$ solutions were chosen as $0.1,0.4,0.7,1.0$,

2.0, $3.0 \mathrm{~mol} / \mathrm{L}$. The tubes were then sealed firmly to avoid carbonation and stored at $20 \pm 1{ }^{\circ} \mathrm{C}$ until no change in chloride concentration of external $\mathrm{NaCl}$ solution was detected within 5 days. After equilibrium adsorption, the external solution was acidified by adding $1 \mathrm{~mL}(1: 1)$ nitric acid and then the chloride concentration was tested by potentiometric titration to avoid generating a sepia precipitation $\left(\mathrm{Ag}_{2} \mathrm{O}\right.$ due to oxidation of silver ion in alkaline solution). The amount of bound chloride in the PC-GBFS pastes was regarded as the reduced chloride in the external solution after equilibrium binding isotherm, and can be calculated by:

$$
C_{b}=35.453 \times V_{0} \times\left(C_{i}-C_{l}\right) / m
$$

where, $C_{b}$ is the amount of bound chloride in hydrated cement paste $(\mathrm{mg} / \mathrm{g}) ; C_{i}$ and $C_{l}$ are the chloride concentrations of the external solution before and after binding isotherm test (mol/L); $V_{0}$ is the volume of the external solution $(\mathrm{mL}) ; m$ is the dry mass of the hydrated cement paste $(\mathrm{g})$.

After equilibrium binding, samples were taken out from $\mathrm{NaCl}$ solution and freeze-dried. Then the samples were crashed into small pieces $(<0.85 \mathrm{~mm})$ and boiled in distilled water, and water-soluble chloride content was measured according to ASTM C1218 [27].

\subsubsection{BET specific surface area measurement}

The hydrated PC-GBFS pastes were dried and ground into powder passing through $80 \mu \mathrm{m}$ sieve. The obtained powders were outgassed in a surface area analyzer (ASAP2020N, Micromeritics instrument) at 
$40{ }^{\circ} \mathrm{C}$ for $6 \mathrm{~h}$, and then $\mathrm{N}_{2}$ physisorption test was carried out to measure Brunauer Emmett Teller (BET)

specific surface area by Eq. (2) [28].

$$
\frac{1}{W\left(P_{0} / P-1\right)}=\frac{1}{W_{m} C}+\frac{C-1}{W_{m} C}\left(\frac{P}{P_{0}}\right)
$$

where, $W$ is the mass of adsorbed $\mathrm{N}_{2}$ at a given relative pressure $\left(P / P_{0}\right) ; W_{m}$ is the mass of single layer adsorbate on the surface of cement paste; $C$ is a constant related to the first layer adsorption capacity, indicating the interaction between adsorbate and adsorbent.

The mass of single layer adsorbate $\left(W_{m}\right)$ on the surface of hydrated cement paste can be calculated by Eq. (3).

$$
W_{m}=\frac{1}{S+I}
$$

where, $S$ and $I$ are the slope and intercept of adsorption lines between $1 /\left[W\left(P_{0} / P-1\right)\right]$ and $P_{0} / P$ as shown in Eq. (2).

Finally, the BET specific surface area of hydrated cement paste can be calculated:

$$
\mathrm{S}=\frac{W_{m} N A_{C S}}{M W}
$$

where, $N$ is Avogadro's constant $\left(6.023 \times 10^{23} / \mathrm{mol}\right) ; M$ is the molecular mass of adsorbate $(28.013 \mathrm{~g} / \mathrm{mol})$;

$A_{c s}$ is the molecular cross-sectional area of adsorbate $\left(16.2 \AA^{2}\right)$.

\subsubsection{Characterization methods for hydration products}

The hydration products and microstructure of the PC-GBFS pastes were characterized using a scanning electric microscope (SEM, Nova NanoSEM 430, $10 \mathrm{kV}$ ) equipped with an Oxford INCA XMax energy dispersive spectrometer (EDS). Pure compounds or oxides (wollastonite for calcium, $\mathrm{SiO}_{2}$ 
for silicon and oxygen, $\mathrm{Al}_{2} \mathrm{O}_{3}$ for aluminum, $\mathrm{MgO}$ for magnesium) were used as the standard sample, and ZAF corrections were also automatically performed during EDS analysis, then the $\mathrm{Ca} / \mathrm{Si}$ and $\mathrm{Al} / \mathrm{Si}$ molar ratios of hydration products were calculated according to elemental composition obtained by EDS point analysis on polished samples.

A PANalytical X'Pert Pro MPD diffractometer using $\mathrm{Cu} \mathrm{K}_{\alpha}$ radiation $(\lambda=1.54 \AA)$ was used to identify the crystalline phases in the cement pastes. The mineral composition changes were examined before and after chloride binding isotherm by comparing the X-ray diffraction (XRD) patterns of the PC-GBFS pastes. A nuclear magnetic resonance spectrometer (NMR, Bruker AVANCE digital 400 MAS) was employed to characterize the microstructure of hydration products in the PC-GBFS pastes. The ${ }^{29} \mathrm{Si} \mathrm{NMR}$ spectra was acquired at a spinning speed of $5 \mathrm{k} \mathrm{Hz}$, relaxation time of $5 \mathrm{~s}$, single-pulse excitation with a pulse width of $6 \mu$ s, and typically 5000 scans, and the ${ }^{29} \mathrm{Si}$ chemical shifts were referenced to those of neat trimethylsilane (TKS). The ${ }^{27} \mathrm{Al} \mathrm{NMR} \mathrm{spectra} \mathrm{was} \mathrm{obtained} \mathrm{at} \mathrm{a} \mathrm{spinning} \mathrm{speed} \mathrm{of} 13 \mathrm{k} \mathrm{Hz}$, relaxation time of $2 \mathrm{~s}$, a pulse width of $0.5 \mu \mathrm{s}$, and $6200 \mathrm{scans}$, and the ${ }^{27} \mathrm{Al}$ chemical shifts were referenced to those of $1.0 \mathrm{~mol} / \mathrm{L}$ aqueous solution of $\mathrm{AlCl}_{3} \cdot 6 \mathrm{H}_{2} \mathrm{O}$. To quantify the Friedel's salt content, thermogravimetric analysis (TGA, Netzsch STA449C F5) was carried out on the PC-GBFS pastes after chloride adsorption under heating temperature up to $1000{ }^{\circ} \mathrm{C}$, heat rate of $10{ }^{\circ} \mathrm{C} / \mathrm{min}$, and protection flow of $50 \mathrm{ml} / \mathrm{min} \mathrm{N}_{2}$.

\section{The hydration heat and chemical shrinkage of the PC-GBFS binder}

As shown in Fig. 2a, the heat evaluation peak in the range of 2-8 $\mathrm{h}$ was attributed to the hydration of $\mathrm{C}_{3} \mathrm{~A}$ and $\mathrm{C}_{3} \mathrm{~S}$ of Portland cement clinker, with a shoulder centered at about $11 \mathrm{~h}$ corresponded to the 
formation of AFt, and a broad peak ranged from $8 \mathrm{~h}$ to $20 \mathrm{~h}$ was assigned to the hydration of GBFS. Pure

Portland cement paste had a pronounced peak and a shoulder at about $5 \mathrm{~h}$ and $11 \mathrm{~h}$, respectively,

presenting significant hydration of clinker phases in Portland cement. With the increase of GBFS addition,

the heat evaluation peak of clinker declined sharply, whereas the heat evaluation peak of GBFS increased

dramatically. Pure GBFS paste had a much wider heat evaluation peak initiated from about $1 \mathrm{~h}$ and ended

at approximately $200 \mathrm{~h}$, while the corresponding peak was relatively narrower, indicating the hydration

of GBFS concentrated in 8-24 $\mathrm{h}$ in the presence of $\mathrm{CH}$. Generally, the hydration heat of cement pastes

decreased with the increase of the GBFS addition. However, Fig. $2 b$ indicates that the cement pastes with

$20 \%$ or $40 \%$ GBFS had higher ultimate hydration heat compared to the Portland cement paste, though

the cement pastes with GBFS had a slower hydration heat development, particularly when large amount

of GBFS was added. The cement paste with $60 \%$ GBFS had nearly equal ultimate hydration heat with

the Portland cement paste, then the ultimate hydration heat reduced remarkably when the GBFS addition

was further increased. It can be inferred that adding small amount of ultrafine GBFS may increase the

hydration heat due to synergistic hydration of clinker and GBFS.

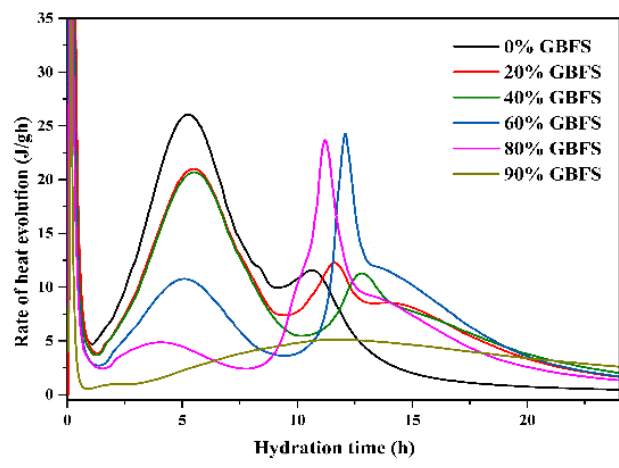

(a) Rate of heat evaluation

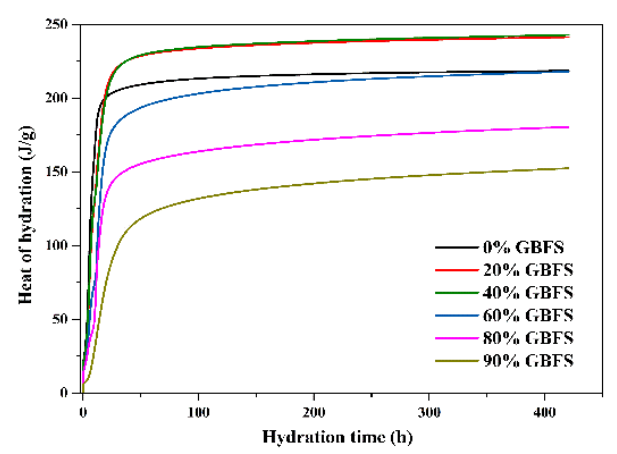

(b) Heat of hydration

Fig. 2 Heat evaluation of the PC-GBFS pastes with W/B of 0.5 
As shown in Fig. 3, the chemical shrinkage developed much slower with the increase of GBFS addition,

while the ultimate chemical shrinkage increased gradually. When the GBFS addition was within $60 \%$,

small difference in chemical shrinkage was observed, whereas cement pastes with $80 \%$ or more GBFS

had much lower early chemical shrinkage at early ages and higher ultimate chemical shrinkage. For

example, the 3 days and 60 days chemical shrinkages of Portland cement were $5.93 \mathrm{~mL} / 100 \mathrm{~g}$ and 7.77

$\mathrm{mL} / 100 \mathrm{~g}$, respectively, and those of the PC-60\% GBFS were $5.20 \mathrm{~mL} / 100 \mathrm{~g}$ and $8.11 \mathrm{~mL} / 100 \mathrm{~g}$, and changed to $1.07 \mathrm{~mL} / 100 \mathrm{~g}$ and $9.34 \mathrm{~mL} / 100 \mathrm{~g}$ for $100 \%$ GBFS, indicating that GBFS resulted in larger chemical shrinkage compared with Portland cement at equal hydration degree.

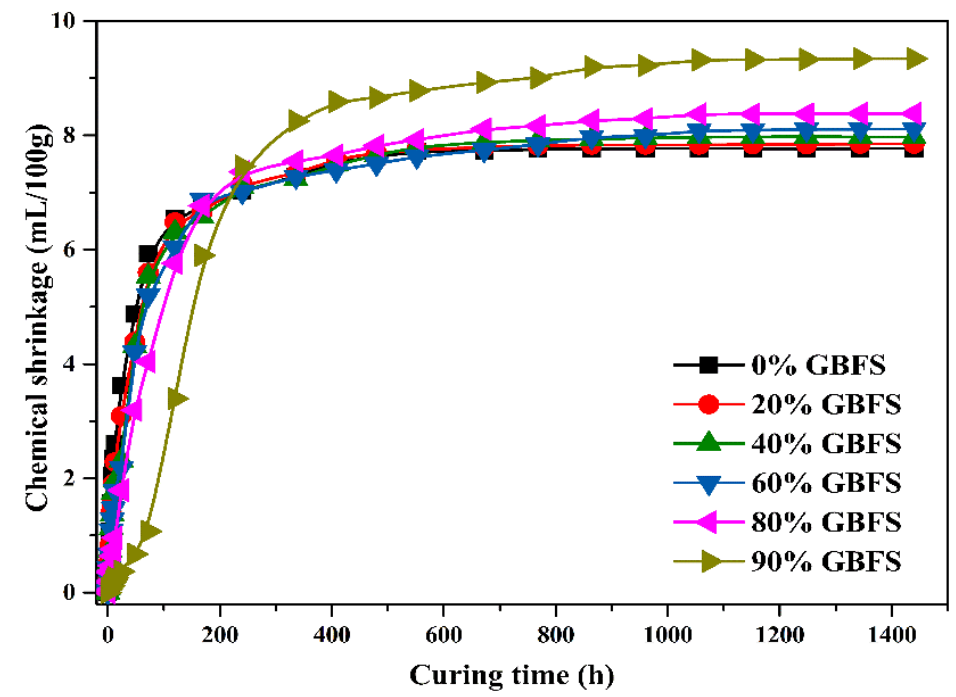

Fig. 3 The chemical shrinkage of PC-GBFS binder at $20^{\circ} \mathrm{C}$

\section{Chloride binding capacity and stability of the PC-GBFS pastes}

\subsection{Binding isotherm of the PC-GBFS pastes}

Fig. 4 shows the chloride binding isotherms of the PC-GBFS pastes as a function of the concentration of $\mathrm{NaCl}$ solution. The relationship between the amount of bound chloride $\left(\mathrm{C}_{\mathrm{b}}\right)$ and the free chloride 
concentration $\left(\mathrm{C}_{\mathrm{f}}\right)$ can be described by Freundlich isotherm [13], and the fitting parameters are listed in

Table 4. The chloride binding capacity of all PC-GBFS pastes increased with the concentration of external chloride solutions. Specifically, the bound chloride mounted up initially at low chloride concentration and then slowed down at high chloride concentration. Notably, the incorporation of GBFS was beneficial to increase the chloride binding capacity, and 40\% GBFS addition led to the highest chloride binding capacity compared to other additions.

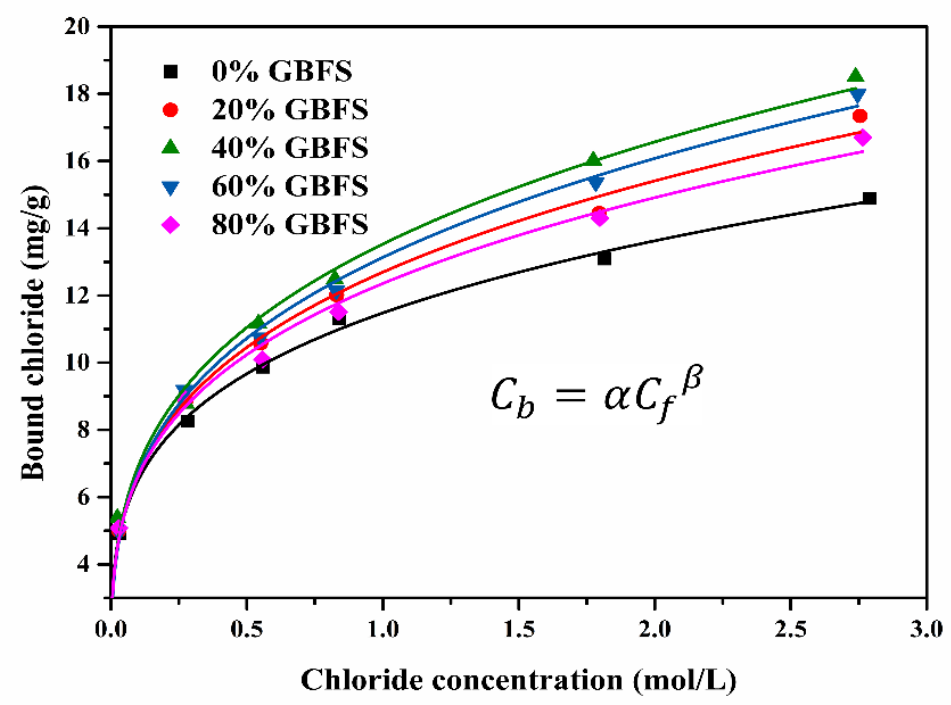

Fig. 4 Chloride binding isotherms of the PC-GBFS pastes

Table 4. Fitting parameters of Freundlich isotherms of the PC-GBFS pastes

\begin{tabular}{cccc}
\hline \multirow{2}{*}{ GBFS addition (\%) } & \multicolumn{2}{c}{ Parameter } & \multirow{2}{*}{$\mathrm{R}^{2}$} \\
\cline { 2 - 4 } & $\alpha$ & $\mathrm{B}$ & 0.997 \\
0 & 11.48 & 0.247 & 0.992 \\
40 & 12.69 & 0.290 & 0.987 \\
60 & 13.53 & 0.292 & 0.995 \\
80 & 13.13 & 0.271 & 0.990 \\
\hline
\end{tabular}

\subsection{Phase assemblage changes of the PC-GBFS pastes}

Phase assemblage changes of the PC-GBFS pastes exposed to $\mathrm{NaCl}$ solutions are shown in Fig. 5.

As the concentration of $\mathrm{NaCl}$ solution increased, the intensity of diffraction peaks corresponding to 
Friedel's salt increased significantly, while the diffraction peak intensity of ettringite increased initially and then decreased afterward (Fig. 5a). The phenomenon can be attributed to that $\mathrm{SO}_{4}{ }^{2-}$ in $\mathrm{AFm}$ crystal can be substituted by $\mathrm{Cl}^{-}$and then to form ettringite in a low concentration $\mathrm{NaCl}$ solution [29], and ettringite decomposed to form new AFm when the original AFm has been consumed completely in a high concentration $\mathrm{NaCl}$ solution. In Fig. 5b, the diffraction peaks of ettringite and calcite decreased with the increase of the GBFS addition, and those of Friedel's salt increased initially and then decreased when the GBFS addition was higher than $60 \%$. Calcite in cement paste was attributed to the carbonation of hydration products (mainly $\mathrm{Ca}(\mathrm{OH})_{2}$ ) during sampling, and more $\mathrm{Ca}(\mathrm{OH})_{2}$ was consumed with the increase of GBFS addition, leading to a reduction in the $\mathrm{Ca}(\mathrm{OH})_{2}$ content. Though GBFS contains higher $\mathrm{Al}_{2} \mathrm{O}_{3}$ content that can potentially lead to more AFm phase and transform to Friedel's salt in $\mathrm{NaCl}$ solution, the amount of $\mathrm{SO}_{4}{ }^{2-}$ available decreased with the increase of the GBFS addition, resulting in less ettringite and AFm and finally decreased amount of Friedel's salt.

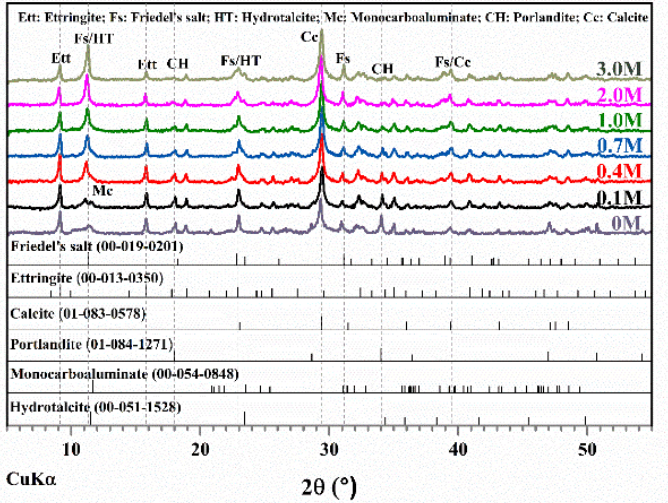

(a) PC-40\% GBFS pastes exposed to different $\mathrm{NaCl}$ solutions exposed to $3.0 \mathrm{~mol} / \mathrm{L} \mathrm{NaCl}$ solution Fig. 5 XRD patterns of the PC-GBFS pastes exposed to $\mathrm{NaCl}$ solutions

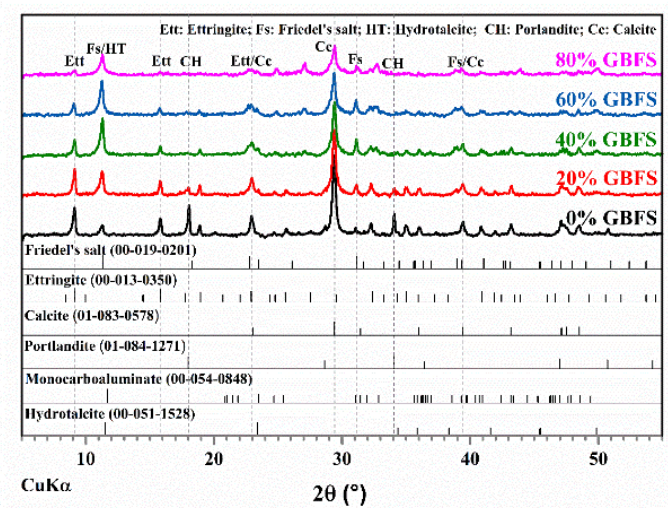

(b) Cement pastes with different GBFS addition

\subsection{Chloride binding capacity of the PC-GBFS pastes}


As shown in the DTG curves (Fig. 6), the sharp weight loss in the range of $50-200^{\circ} \mathrm{C}$ attributes to the water loss from C-S-H, ettringite, and Friedel's salt (mainly 4 mol interlayer water, Eq. 5), whereas that ranged from $230{ }^{\circ} \mathrm{C}$ to $370{ }^{\circ} \mathrm{C}$ only relates to the loss of 6 molecule main-layer water released from Friedel's salt as presented by Eq. 6 [30]. Commonly, weight losses in the range of $390-450{ }^{\circ} \mathrm{C}$ and 580-

$700{ }^{\circ} \mathrm{C}$ correspond to the decomposition of portlandite and calcite, respectively.

$$
\begin{gathered}
\mathrm{Ca}_{4} \mathrm{Al}_{2} \mathrm{Cl}(\mathrm{OH})_{12} \cdot 4 \mathrm{H}_{2} \mathrm{O} \stackrel{170^{\circ} \mathrm{C}}{\longrightarrow} \mathrm{Ca}_{4} \mathrm{Al}_{2} \mathrm{Cl}(\mathrm{OH})_{12}+4 \mathrm{H}_{2} \mathrm{O} \uparrow \\
\mathrm{Ca}_{4} \mathrm{Al}_{2} \mathrm{Cl}(\mathrm{OH})_{12} \stackrel{230-370^{\circ} \mathrm{C}}{\longrightarrow} \mathrm{Ca}_{4} \mathrm{Al}_{2} \mathrm{ClO}_{6}+6 \mathrm{H}_{2} \mathrm{O} \uparrow
\end{gathered}
$$

As shown in Fig. 6a, the weight loss at $230-370{ }^{\circ} \mathrm{C}$ related to Friedel's salt became more and more pronounced with the increase of chloride concentration, whereas the weight loss due to decomposition of $\mathrm{CH}$ became less pronounced. With the increase of the chloride concentration, the weight loss assigned to 6 molecule main-layer water released from Friedel's salt increased gradually. In contrast, the weight loss assigned to Friedel's salt increased and then declined with the increase of GBFS addition, and it can be inferred that the cement paste with 40\% GBFS had highest Friedel's salt content as shown in Fig. 6 b.

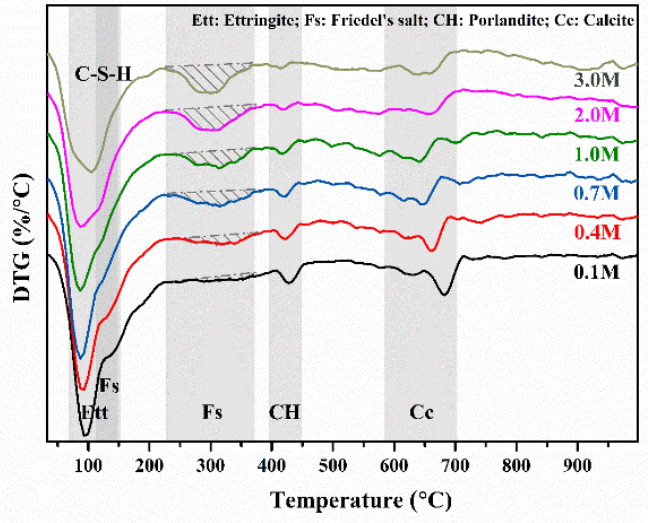

(a) $\mathrm{PC}-40 \%$ GBFS pastes exposed to different $\mathrm{NaCl}$ solutions exposed to $3.0 \mathrm{~mol} / \mathrm{L} \mathrm{NaCl}$ solution

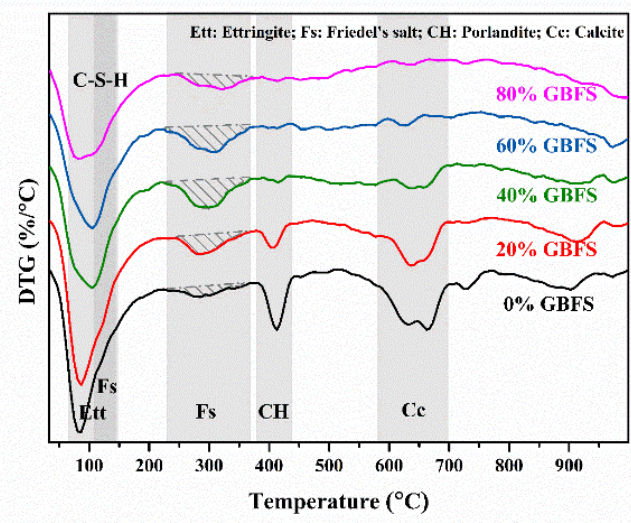

(b) Cement pastes with different GBFS addition

Fig. 6 DTG curves of the PC-GBFS pastes exposed to $\mathrm{NaCl}$ solutions 
The weight loss in the range of $230-370{ }^{\circ} \mathrm{C}$ was calculated and then calibrated based on the DTG curves of the PC-GBFS pastes without immersion in $\mathrm{NaCl}$ solution, then the content of Friedel's salt in the PC-GBFS pastes was calculated according to Eq. 7 [31]:

$$
w_{F s}=\frac{M_{F s}}{6 \times M_{w}} w_{w}=\frac{M_{F s}}{6 \times M_{w}} \cdot S_{w}
$$

where, $w_{F s}$ is the content of Friedel's salt in cement paste (wt.\%), $w_{w}$ is the weight loss of 6 molecule main-layer water released from Friedel's salt (wt.\%), $S_{w}$ is the integral area of the peak in the range of 230-370 ${ }^{\circ} \mathrm{C}$ in DTG curves (\%), $M_{F s}$ and $M_{w}$ are the molar masses of Friedel's salt $(561.3 \mathrm{~g} / \mathrm{mol})$ and $\mathrm{H}_{2} \mathrm{O}(18.02 \mathrm{~g} / \mathrm{mol})$, respectively.

For cement paste with $40 \%$ GBFS, the Friedel's salt content increased from $3.22 \%$ to $10.65 \%$ with the increase of chloride concentration (Table 5). After adsorption in $3.0 \mathrm{~mol} / \mathrm{L} \mathrm{NaCl}$ solution, the Friedel's salt content in pure Portland cement paste was 3.6\%, and increased to $10.65 \%$ for the cement paste with $40 \%$ GBFS. The content of Friedel's salt, however, reduced to $5.51 \%$ when $80 \%$ GBFS was added into cement paste, which was consistent with the results of XRD analysis (Fig. 5).

Table 5. The Friedel's salt content in the PC-GBFS pastes calculated based on the weight loss in the range of 230$370{ }^{\circ} \mathrm{C}$

\begin{tabular}{cccc}
\hline $\begin{array}{c}\text { Chloride concentration } \\
(\mathrm{mol} / \mathrm{L})\end{array}$ & Friedel's salt content $(\%)$ & $\mathrm{Ca}(\mathrm{OH})_{2}$ content $(\%)$ & $\mathrm{CaCO}_{3}$ content $(\%)$ \\
\hline 0.1 & 3.22 & 1.78 & 3.60 \\
0.4 & 4.87 & 1.48 & 3.48 \\
0.7 & 6.70 & 1.14 & 3.23 \\
1.0 & 7.55 & 1.35 & 3.53 \\
2.0 & 9.52 & 0.67 & 3.46 \\
3.0 & 10.65 & 0.55 & 2.01 \\
\hline GBFS addition (\%) & Friedel's salt content $(\%)$ & & 7.89 \\
\hline 0 & 3.60 & 5.86 & 5.80 \\
20 & 6.57 & 2.07 & 2.01 \\
40 & 10.65 & 0.55 & 0.63 \\
60 & 9.69 & 0.42 & 0.26 \\
\hline
\end{tabular}




\subsection{Chloride binding stability of the PC-GBFS pastes}

To evaluate the stability of bound chloride, desorption test was carried out on the PC-GBFS pastes after equilibrium binding in $3 \mathrm{~mol} / \mathrm{L} \mathrm{NaCl}$ solution. Table 6 indicates that more than $60 \%$ of bound chloride in all PC-GBFS pastes is water-soluble chloride, which can be released into water. Notably, only $13.8 \%$ of bound chloride $(2.05 \mathrm{mg} / \mathrm{g})$ was non-water-soluble chloride for pure Portland cement paste, whereas the non-water-soluble chloride content of the cement paste with $40 \%$ GBFS was $7.51 \mathrm{mg} / \mathrm{g}$, contributing to $40.61 \%$ of total bound chloride. Although the total bound chloride of the cement paste with $40 \%$ GBFS was only increased by $24 \%$ compared with that of Portland cement paste, the amount of non-water-soluble chloride was increased by $266 \%$, which might lead to significant improvement of chloride resistance when cement-based materials exposed to chloride-rich environments. Additionally, the amount of non-water-soluble chloride was obviously less than the amount of chemically bound chloride calculated based on the DTG curves, illustrating that partial of chemically bound chloride may be released when exposed to water or low chloride concentration solution $[2,29]$.

Table 6. The distribution of bound chloride in the PC-GBFS pastes after equilibrium adsorption in $3 \mathrm{~mol} / \mathrm{L} \mathrm{NaCl}$ solution

\begin{tabular}{ccccc}
\hline $\begin{array}{c}\text { Sample } \\
\text { ID }\end{array}$ & $\begin{array}{c}\text { Total bound chloride } \\
(\mathrm{mg} / \mathrm{g})\end{array}$ & $\begin{array}{c}\text { Water-soluble chloride } \\
(\mathrm{mg} / \mathrm{g})\end{array}$ & $\begin{array}{c}\text { Non-water-soluble } \\
\text { Chloride }(\mathrm{mg} / \mathrm{g})\end{array}$ & Solidification ratio (\%) \\
\hline G0 & 14.88 & 12.83 & 2.05 & 13.8 \\
G2 & 17.34 & 12.39 & 4.95 & 28.6 \\
G4 & 18.50 & 10.99 & 7.51 & 40.6 \\
G6 & 17.99 & 11.54 & 6.45 & 35.9 \\
G8 & 16.70 & 12.40 & 4.30 & 25.8 \\
\hline
\end{tabular}

From the DTG curves (Fig. 7) of the PC-GBFS pastes after desorption, the weight loss peak at 230-

$370{ }^{\circ} \mathrm{C}$ related to Friedel's salt became less pronounced for all PC-GBFS pastes, indicating that partial of chloride in Friedel's salt may be released, or the Friedel's salt is not stable when the chloride concentration of external solutions reduced. The reason may lies in that the nature of Friedel's salt is a 
kind of layered double hydroxides, like hydrotalcite, the anions in the interlayer of Friedel's salt can be substituted to form monosulfoaluminate, or monocarbonaluminate [29].

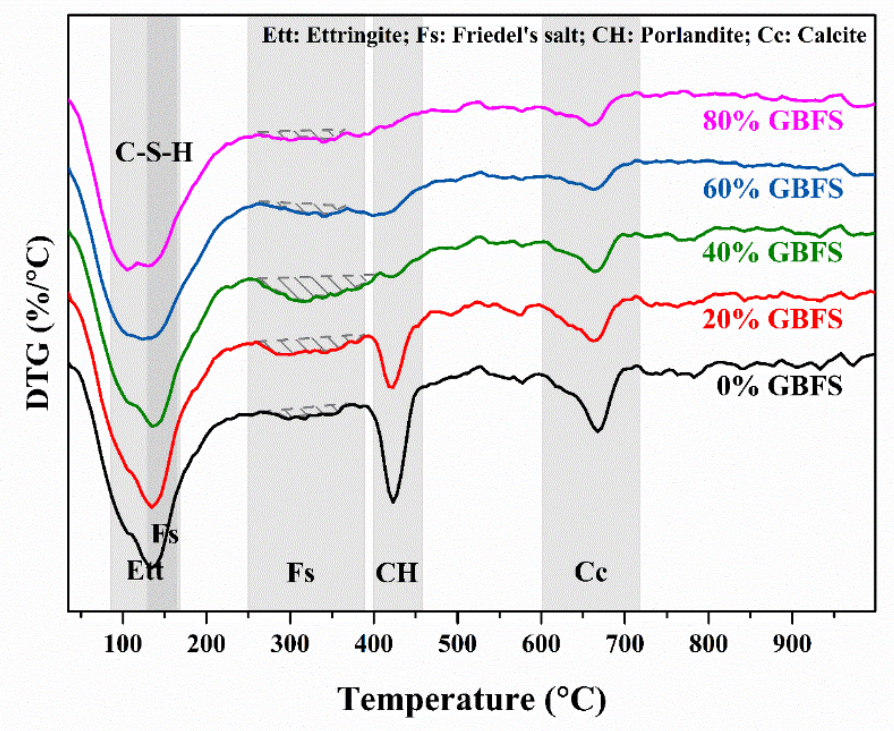

Fig. 7 DTG curves of the PC-GBFS pastes after desorption in distilled water

Generally, a proportion of bound chloride is existed in terms of Friedel's salt, and the rest bound chloride is physically adsorbed on the surface of C-S-H gel. These two forms of bound chloride, in terms of chemically bound chloride and physically bound chloride, are further classified according to Eq. 8 and 9.

$$
\begin{array}{r}
C_{F S}=\frac{2 M_{C l} \times 10}{M_{F s}} w_{F S} \\
C_{C}=C_{b}-C_{F S}
\end{array}
$$

where, $C_{b}$ is the amount of total bound chloride $(\mathrm{mg} / \mathrm{g}), C_{F s}$ is the amount of chemically bound chloride (mg/g), $C_{C}$ is the amount of physically bound chloride $(\mathrm{mg} / \mathrm{g}), M_{C l}$ is the molar mass of chloride $(35.45$ $\mathrm{g} / \mathrm{mol})$. 
By comparing the amount of bound chlorides before and after desorption as shown in Fig. 8, the stability of chemically and physically bound chlorides was clarified. 5 20\% of physically bound chloride still existed in the hydrated PC-GBFS pastes after desorption in water, presenting about 80 95\% of physically bound chloride was water-soluble chloride (Fig. 9). In contrast, about 35-50\% of chloride in the form of Friedel's salt was measured after desorption in water, suggesting that $50 \sim 65 \%$ of chemically bound chloride was released in water. In other words, the major part of non-water-soluble chloride was from chemically bound chloride in the form of Friedel's salt, the rest (10-25\%) was contributed by physically bound chloride adsorbed by C-S-H. The amount of non-water-soluble chloride in the cement paste with $40 \%$ GBFS was $7.51 \mathrm{mg} / \mathrm{g}$, which was 3.66 times higher than that of pure Portland cement paste $(2.05 \mathrm{mg} / \mathrm{g}$ in Fig. 8), indicating significant improvement in chloride binding capacity. It can be inferred that the chloride resistance of the cement pastes with 40 60\% GBFS can be enhanced dramatically, as much more chloride can be firmly solidified in hydration products, then the migration rate of chloride into the internal paste reduces effectively.

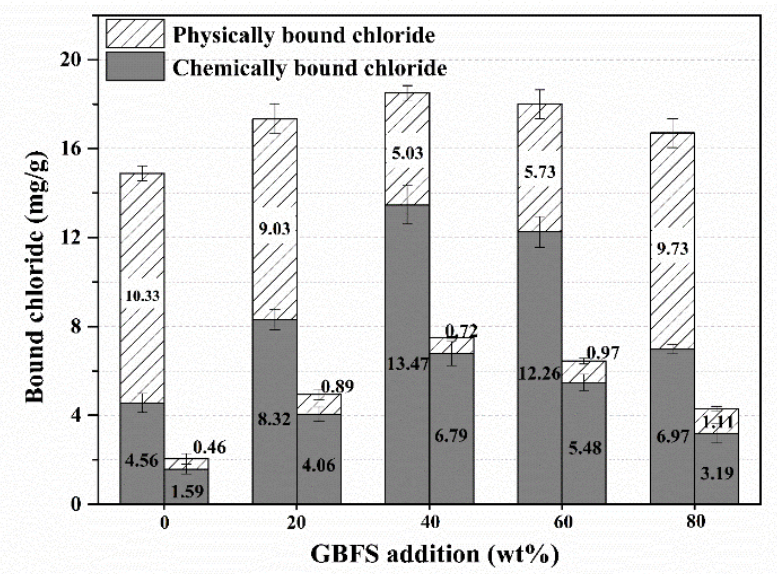

Fig. 8 The amount of chemically and physically bound chlorides of the PC-GBFS pastes before (left column) and after (right column) desorption 


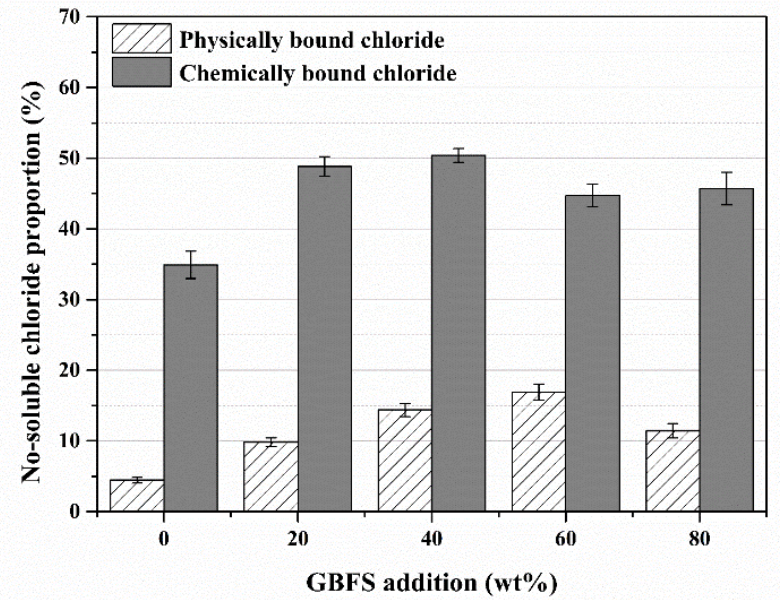

Fig. 9 Proportion of non-water-soluble chloride in chemically and physically bound chlorides

\section{The characteristics of hydration products in the PC-GBFS pastes}

Since ultrafine Portland cement and ultrafine GBFS were used, the PC-GBFS pastes had high hydration degree after 28 days curing ( $>85 \%$ ) according to previous investigation [32], then hydration products were characterized to clarify the influence of GBFS.

\subsection{BET specific surface area}

As shown in Fig. 10, the BET specific surface area of the hydrated cement pastes increased linearly with the increase of the GBFS proportion. For instance, pure Portland cement paste had a specific surface area of $54.7 \mathrm{~m}^{2} / \mathrm{g}$, whereas that of the cement paste with $80 \%$ GBFS was up to $146.4 \mathrm{~m}^{2} / \mathrm{g}$, indicating that hydration products of the PC-GBFS pastes had a larger internal specific surface area, which might lead to a larger chloride binding capacity. 


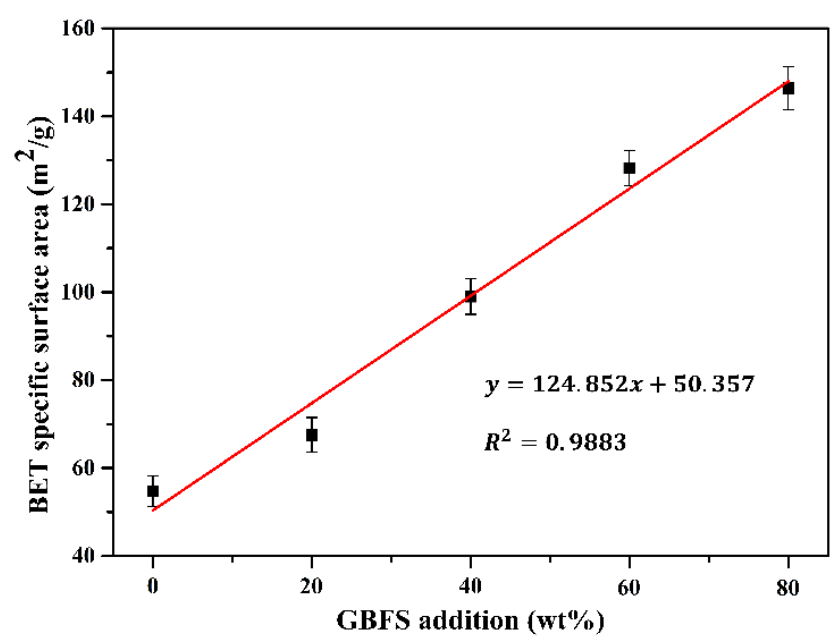

Fig. 10 BET specific surface area of the hydrated cement pastes with GBFS

\subsection{The $\mathrm{Ca} / \mathrm{Si}$ and $\mathrm{Al} / \mathrm{Si}$ molar ratios of hydration products}

The $\mathrm{Ca} / \mathrm{Si}$ and $\mathrm{Al} / \mathrm{Si}$ molar ratios of hydration products were calculated based on the EDS results of more than fifty spot-analyses of the polished PC-GBFS pastes. As shown in Fig. 11, with the increase of GBFS addition in the PC-GBFS pastes, the $\mathrm{Ca} / \mathrm{Si}$ molar ratio of hydration products declined, whereas the Al/Si molar ratio increased linearly. The phenomenon can be attributed to that the hydration of GBFS consumed considerable amount of $\mathrm{Ca}(\mathrm{OH})_{2}$ to form $\mathrm{C}-\mathrm{S}-\mathrm{H}$ gel with lower $\mathrm{Ca} / \mathrm{Si}$ molar ratio and higher $\mathrm{Al} / \mathrm{Si}$ molar ratio, as $\mathrm{Si}$ in the main chain of $\mathrm{C}-\mathrm{S}-\mathrm{H}$ gel was substituted by Al originated from GBFS to form C-A-S-H gels, resulting in a larger chloride binding capacity due to higher binding site density for chloride $[33,34]$.

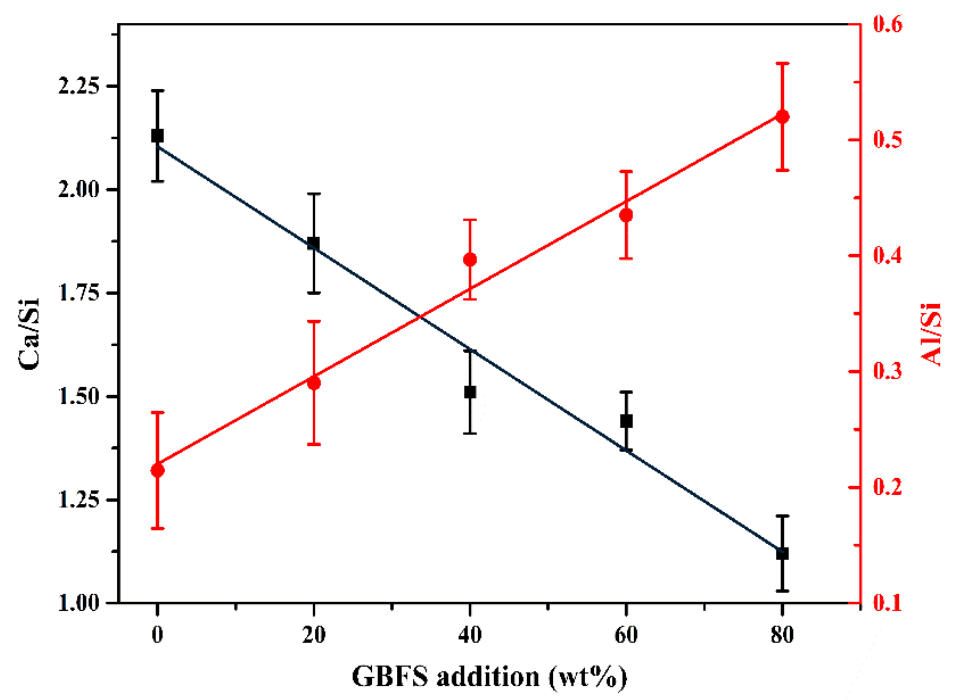

Fig. $11 \mathrm{The} \mathrm{Al} / \mathrm{Si}$ and $\mathrm{Ca} / \mathrm{Si}$ molar ratios of hydration products in the PC-GBFS pastes 


\subsection{The main chain of C-S-H gel}

Changes in the main chain of C-S-H gel is evaluated by solid state NMR spectra. The peak around $75 \mathrm{ppm}$ in ${ }^{29} \mathrm{Si}$ spectra represents $\mathrm{Q}^{0}$ silicate tetrahedron in the form of $\mathrm{C}_{3} \mathrm{~S}$ and $\mathrm{C}_{2} \mathrm{~S}$ as shown in Fig. 12, and the broad band from -76 to $-82 \mathrm{ppm}$ is also the resonance peak of $\mathrm{Q}^{0}$ silicate tetrahedron in residual GBFS. $\mathrm{Q}^{1}$ and $\mathrm{Q}^{2}$ present the end-chain silicate tetrahedron and middle-chain silicate tetrahedron, respectively. And the $\mathrm{Q}^{2}$ peak can be further classified into $\mathrm{Q}^{2 \mathrm{~B}}, \mathrm{Q}^{2 \mathrm{P}}$ and $\mathrm{Q}^{2}(1 \mathrm{Al})$, which are bridging silicate tetrahedron, paired silicate tetrahedron, and bridging silicate tetrahedron with substitution of $\mathrm{Al}$ for $\mathrm{Si}$, respectively [35]. With the increase of GBFS addition, the intensity of $\mathrm{Q}^{0}$ peak related to $\mathrm{C}_{2} \mathrm{~S}$ and $\mathrm{C}_{3} \mathrm{~S}$ decreased sharply, while the broad peak assigned to GBFS increased slightly. More importantly, the peak from -80 to $-90 \mathrm{ppm}$ became more pronounced with the increase of GBFS addition, indicating a higher proportion of $\mathrm{Q}^{2}$ and a decreased amount of $\mathrm{Q}^{1}$. Therefore, the chain structure of hydration products in cement paste with GBFS was fairly different from that in PC, as abundant Al from GBFS was incorporated into C-S-H gel [36]. 


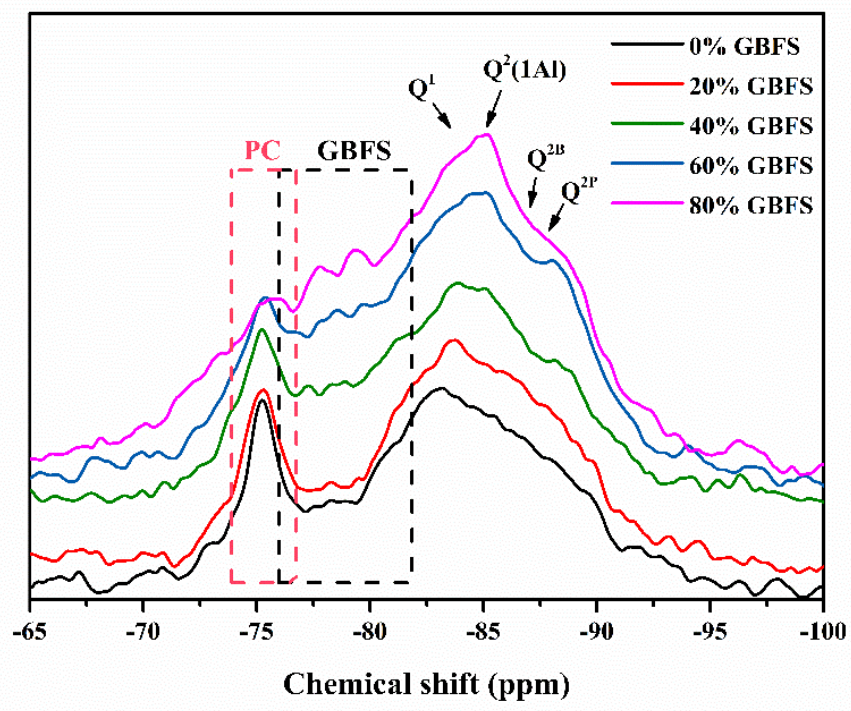

Fig. 12 The ${ }^{29} \mathrm{Si}$ MAS NMR spectra of the hydrated PC-GBFS pastes

According to the location of $\mathrm{Q}^{\mathrm{n}}$, a peak-fit process was carried out on the NMR spectra (Fig. 13), the amount of $\mathrm{Q}^{\mathrm{n}}$ was quantified and then the mean chain length (MCL) of C-S-H gel was calculated by Eq.

10.

$$
\mathrm{MCL}=\frac{2}{\frac{Q^{1}}{Q^{1}+Q^{2}}}=\frac{2}{\frac{Q^{1}}{Q^{1}+Q^{2}(0 A l)+\frac{3}{2} Q^{2}(1 A l)}}=\frac{2}{\frac{Q^{1}}{Q^{1}+Q^{2 B}+Q^{2 P}+\frac{3}{2} Q^{2}(1 A l)}}
$$

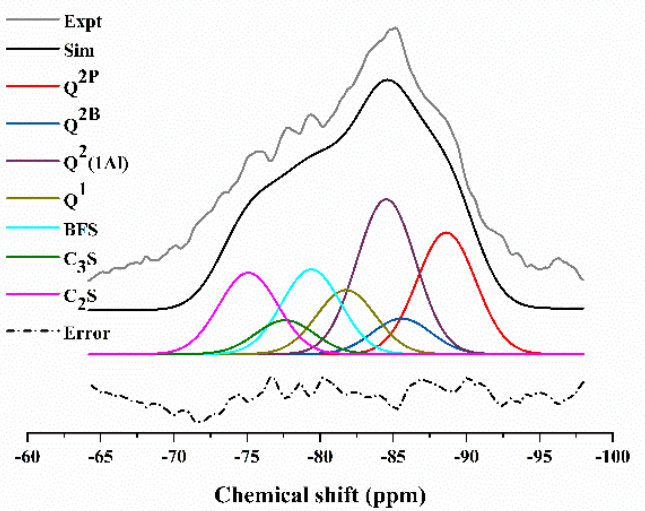

(a) Portland cement paste

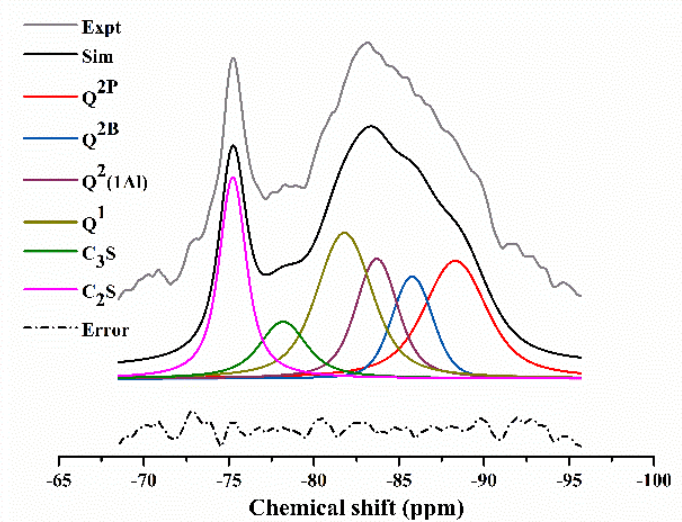

(b) PC-80\% GBFS paste

Fig. 13 Peak-fit process of ${ }^{29} \mathrm{Si}$ NMR spectra of PC and PC-80\% GBFS pastes

Fig. 14 shows the MCL of C-S-H gel increased with the increase of GBFS proportion. While the rising rate slowed down when GBFS exceeded 60 wt.\%. Notably, the MCL of C-S-H gel in the cement paste 
with $80 \%$ GBFS was as high as 8.5 , indicating that the $\mathrm{Al}$ introduced by GBFS mainly substitutes for the Si on the main chain of C-S-H gel and consequently increases the MCL of C-S-H gel.

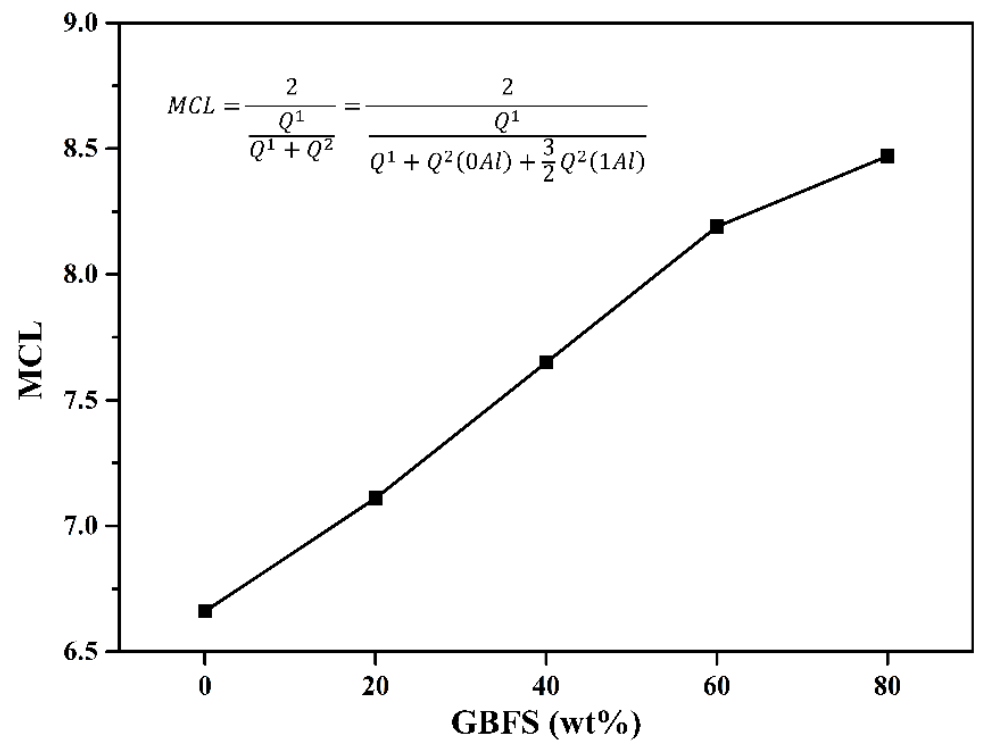

Fig. 14 The MCL of C-S-H gel in the hydrated PC-GBFS pastes

In ${ }^{27} \mathrm{Al}$ spectra (Fig. 15), the coordination number of $\mathrm{Al}$ in hydration products is mainly 4 (Al[IV]), 5 $(\mathrm{Al}[\mathrm{V}])$ and $6(\mathrm{Al}[\mathrm{VI}])$, presenting its different roles. $\mathrm{Al}[\mathrm{IV}]$ exists in the main chain of $\mathrm{C}-\mathrm{A}-\mathrm{S}-\mathrm{H}$ gel instead of silica tetrahedron [37], $\mathrm{Al}[\mathrm{V}]$ only exists at the end, in the interlayer, or on the surface of C$\mathrm{S}-\mathrm{H}$ gel, while $\mathrm{Al}[\mathrm{VI}]$ represents $\mathrm{Al}$ in the structure of ettringite and AFm. As shown in Fig. 15, Al mainly existed as $\mathrm{Al}[\mathrm{VI}]$ in the hydration products of pure $\mathrm{PC}$ paste, whereas $\mathrm{Al}[\mathrm{IV}]$ was gradually predominated in the hydration products of the PC-GBFS pastes with the increase of the GBFS proportion. The finding was consistent with the pronounced $\mathrm{Q}^{2}(1 \mathrm{Al})$ resonance in ${ }^{29} \mathrm{Si}$ MAS NMR spectra, as most of $\mathrm{Al}$ from GBFS was incorporated into C-S-H gel rather than to form AFm or ettringite (identified by XRD (Fig. 5) and EDS (Fig. 11) results). 


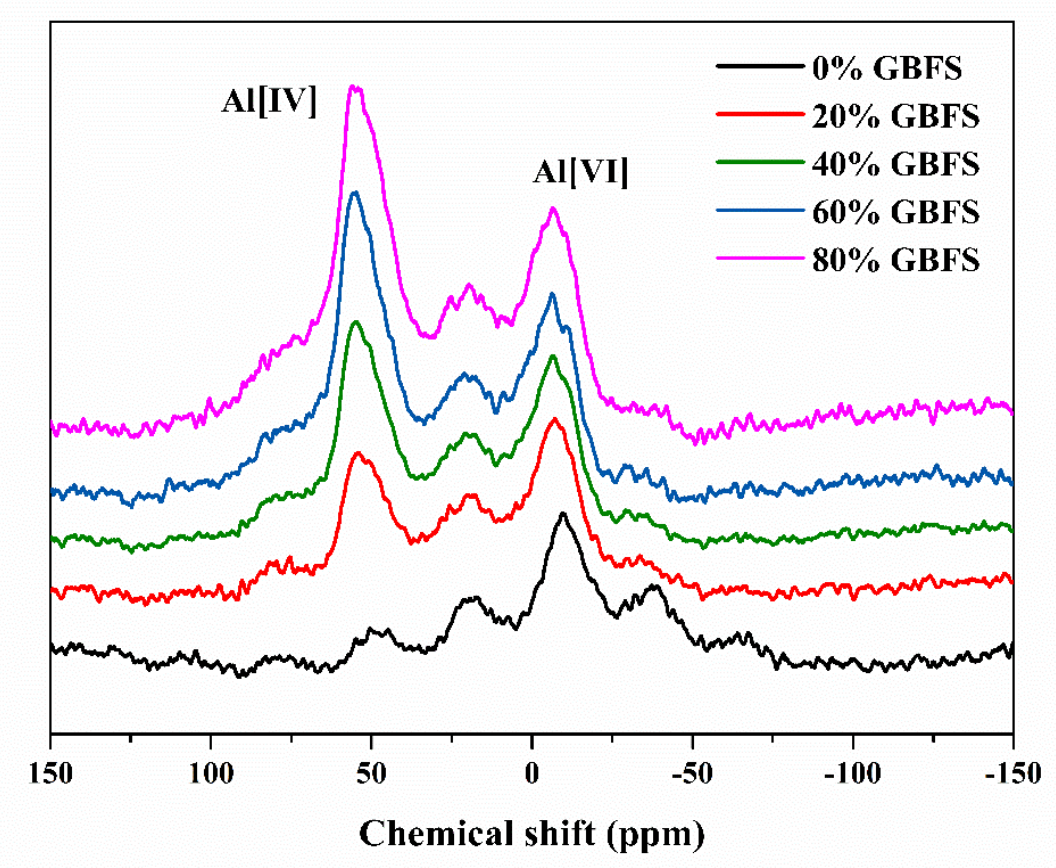

Fig. 15 The ${ }^{27} \mathrm{Al}$ MAS NMR spectra of hydrated PC-GBFS pastes

Table 7. The proportion of $\mathrm{Al}$ with different coordination number in the hydrated PC-GBFS pastes

\begin{tabular}{cccccccc}
\hline \multirow{2}{*}{ GBFS addition } & Total Al content $(\%)$ & \multicolumn{3}{c}{ Absolute content (\%) } & \multicolumn{3}{c}{ Relative content (\%) } \\
\cline { 3 - 7 } & & $\mathrm{Al}[\mathrm{IV}]$ & $\mathrm{Al}[\mathrm{V}]$ & $\mathrm{Al}[\mathrm{VI}]$ & $\mathrm{Al}[\mathrm{IV}]$ & $\mathrm{Al}[\mathrm{V}]$ & $\mathrm{Al}[\mathrm{VI}]$ \\
\hline $0 \%$ & 4.45 & 0.49 & 1.10 & 2.86 & 10.99 & 24.77 & 64.24 \\
$20 \%$ & 8.62 & 3.05 & 1.72 & 3.85 & 35.37 & 19.99 & 44.64 \\
$40 \%$ & 10.25 & 4.88 & 1.73 & 3.72 & 44.51 & 17.86 & 37.63 \\
$60 \%$ & 12.79 & 6.86 & 1.94 & 3.99 & 53.67 & 15.16 & 31.17 \\
$80 \%$ & 14.88 & 8.54 & 1.88 & 4.46 & 57.37 & 12.64 & 29.99 \\
\hline
\end{tabular}

\section{Factors influencing the chloride binding stability of the PC-GBFS pastes}

The factors influencing the chloride binding stability of the PC-GBFS pastes were discussed based

on the characteristics of hydration products.

\subsection{The stability of chloride chemically bound in the form of Friedel's salt}

Both Friedel's salt and AFm phases are lamellar double hydroxides constituted by a stacking of positive charged main layers (hydroxylated layers with a stoichiometry of $\left[\mathrm{Ca}_{2} \mathrm{Al}(\mathrm{OH})_{6}\right]^{+}$) separated by interlayered anionic species and water molecules [30]. In the pore solution of cement paste, hydroxyl, carbonate and sulfate ions are dominated in the interlayer of AFm phases, and then the monosulfate and 
monocarbon type AFms are usually formed as shown in Fig. 16. Since the ion-exchange order is: $\mathrm{CO}_{3}^{2-}>$ $\mathrm{SO}_{4}^{2-}>\mathrm{OH}^{-}>\mathrm{Cl}^{-}[29]$, the interlayer monovalent or divalent anions of AFms can be ion-exchanged with external chloride to form Friedel's salt when exposing to chloride-rich environment. However, the chemically bound chloride in Firedel's salt is not stable, particularly when the chloride concentration of the external solution declines, as partial of chloride on the weak points can be replaced by other anions $[13,30]$. About $45-50 \%$ of chloride in Firedel's salt can be released in deionized water, indicating that only about $50 \%$ of chloride is non-water-soluble chloride and firmly bounded in Friedel's salt.

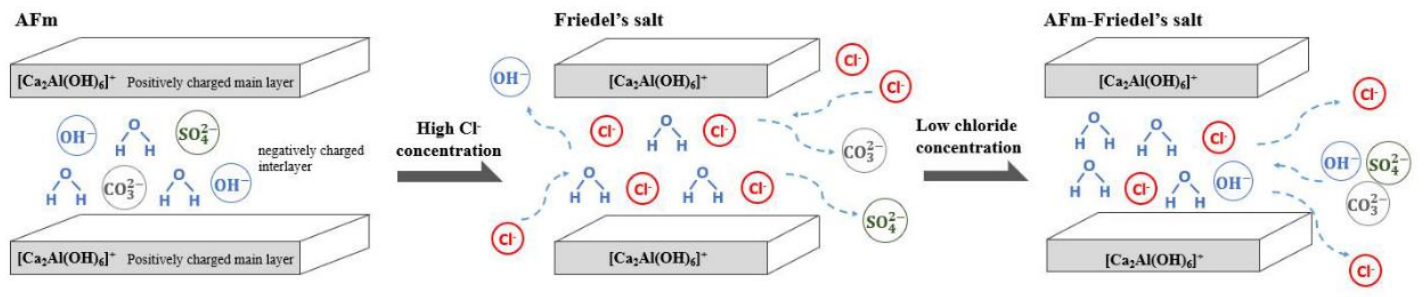

Fig. 16 The illustrating diagrams of conversion between AFm and Friedel's salt under chloride environment

\subsection{The stability of chloride physically bound in C-S-H gel}

As mentioned above, C-S-H gel, the main hydration product, dominates the physically bound chloride due to its large specific surface area. However, the amount of physically bound chloride in the PC-GBFS paste is not proportional to its specific surface area (Fig. 9). The amount of physically bound chloride is reduced initially and then increased sharply, with the increase of the GBFS addition.

On the one hand, with increasing GBFS addition, more $\mathrm{Al}$ is substituted for $\mathrm{Si}$ in the bridging and paring positions of the C-S-H gel, and then two functional surface sites called silanol ( $\equiv \mathrm{Si}-\mathrm{OH})$ and aluminol (=Al-OH) are generated and attached to $\mathrm{Ca}^{2+}$ (as shown in Fig. 17), leading to a higher positive charge density and consequently to a higher physically bound chloride [34,39]. Moreover, the specific 
surface area also increased significantly, which are beneficial to the adsorption of chloride onto the surface of C-S-H gel [40]. On the other hand, the substitution of Al for Si leads to a higher mean chain length and a lower $\mathrm{Ca} / \mathrm{Si}$ molar ratio, indicating higher polymerization degree and protonation degree. Finally, the amount of physically bound chloride reduces sharply due to a lower positive charge density, as the amount of $\mathrm{Ca}$ in $\mathrm{C}-\mathrm{S}-\mathrm{H}$ is reduced with the increase of protonation degree $[33,41]$. It can be inferred that the increase of the polymerization degree and protonation degree are the main reasons leading to a reduction in physically bound chloride, when the GBFS addition is lower than $40 \%$.

Whereas specific surface area and site density are the dominate effects for cement paste with $>60 \%$

GBFS, particularly increase in binding site density leads to dramatic increase in physically bound chloride.

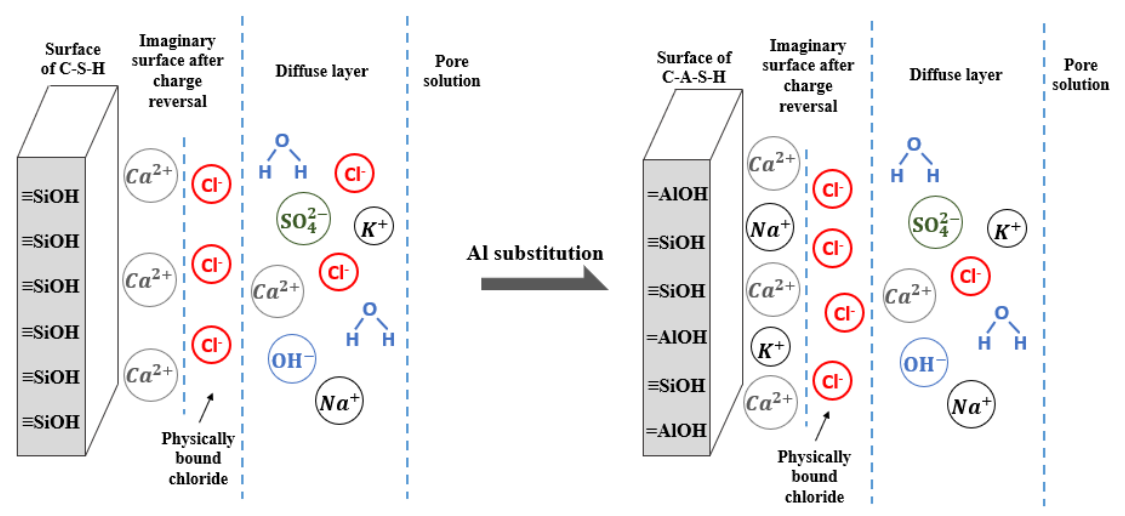

Fig 17. The illustrating diagrams of the chloride physically bound on the surface of C-S-H with/without $\mathrm{Al}$ substitution based on the diffuse double layer theory

Based on the experiment results and above discussion, the cement pastes with 40-60\% GBFS have nearly equal hydration heat and slightly higher chemical shrinkage compared to pure Portland cement paste. More important, the chemically bound chloride is nearly tripled, although the physically bound chloride reduces to about $50 \%$. Notably, the amount of non-water-soluble chloride can be as high as 
$7.51 \mathrm{mg} / \mathrm{g}$, which is 3.66 times as high as that of Portland cement paste, which might result in a desirable chloride resistance and durability.

\section{Conclusions}

Conclusions that can be drawn from the present study are summarized as follows:

(1) The ultimate hydration heat of the PC-GBFS pastes increased initially and then decreased sharply with the increase of ultrafine GBFS addition. Whereas the chemical shrinkage increased slightly with the increase of the GBFS addition.

(2) The total bound chloride of the hydrated PC-GBFS pastes increased initially and then decreased with the increase of GBFS addition. Though the total bound chloride of the cement paste with $40 \%$ GBFS increased by $24 \%$ compared with that of Portland cement paste, the non-water-soluble bound chloride, however, can be 2.77 times as that of Portland cement paste.

(3) 5-20\% of physically bound chloride is non-water-soluble chloride after desorption, and about 50\% of chemically bound chloride was also water-soluble water, indicating chloride in Friedel's salt can be soluble due to its high ion-exchanging ability.

(4) The physically bound chloride was not only influenced by the specific surface area, but also affected significantly by the characteristics of C-S-H gel. Specifically, the substitution of Al for Si in C-S-H gel provided higher binding site density and lager specific surface area, leading to a higher chloride adsorption. Whereas the increase in polymerization degree and protonation degree resulted in a reduction in physically bound chloride. 
(5) Cement pastes with 40-60\% ultrafine GBFS had nearly equal hydration heat and slightly higher chemical shrinkage, and much higher chloride bounding capacity, which will lead to superior cracking resistance and durability.

\section{Acknowledgments}

This work was funded by the National Key Research and Development Program

(2016YFB0303502), Guangdong Science and Technology Program (2016A020221009), the Water

Resource Science and Technology Innovation Program of Guangdong Province (2016-23), the Guangdong Special Support for Youth Science and Technology Innovation Talents (2015TQ01C312), and the Pearl River Science and Technology Nova Program of Guangzhou (201610010098). Their financial supports are gratefully acknowledged.

\section{Reference}

[1] B. Martín-Pérez, H. Zibara, R.D. Hooton, M.D.A. Thomas, A study of the effect of chloride binding on service life predictions, Cem. Concr. Res. 30 (8) (2000) 1215-1223.

[2] Q. Yuan, C. Shi, G. De Schutter, K. Audenaert, D. Deng, Chloride binding of cement-based materials subjected to external chloride environment - a review, Constr. Build. Mater. 23 (1) (2009) $1-13$.

[3] K. Tuutti, Corrosion of steel in concrete, Swedish Cement Concrete Research Institute, Stockholm, 1982.

[4] D.A. Whiting, R.J. Detwiler, E.S. Lagergren, Cracking tendency and drying shrinkage of silica fume concrete for bridge deck applications, Mater. J. 97 (1) (2000) 71-77.

[5] W. Yodsudjai, K. Wang, Chemical shrinkage behavior of pastes made with different types of cements, Constr. Build. Mater. 40 (2013) 854-862.

[6] W. Hansen, Report on early-age cracking - a summary of the latest document from ACI committee 231, Concr. Int. 33 (3) (2011) 48-51.

[7] E.E. Holt, Early age autogenous shrinkage of concrete, Technical Research Centre of Finland, 
Espoo, 2001.

[8] E. Tazawa, S. Miyazawa, T. Kasai, Chemical shrinkage and autogenous shrinkage of hydrating cement paste, Cem. Concr. Res. 25 (2) (1995) 288-292.

[9] H.M. Jennings, B.J. Dalgleish, P. Pratt, Morphological development of hydrating tricalcium silicate as examined by electron microscopy techniques, J. Am. Ceram. Soc. 64 (10) (1981) 567-572.

[10] A.A.M. Neto, M.A. Cincotto, W. Repette, Mechanical properties, drying and autogenous shrinkage of blast furnace slag activated with hydrated lime and gypsum, Cem. Concr. Compos. 32 (4) (2010) 312-318.

[11] S.H. Kosmatka, B. Kerkhoff, W.C. Panarese, Design and control of concrete mixtures, $4^{\text {th }}$ ed., Portland Cement Association, Illinois, 2003

[12] H.A. Berman, Determination of chloride in hardened Portland cement paste, mortar, and concrete, J. Mater. 7 (3) (1972) 330-335.

[13] M.D.A. Thomas, R.D. Hooton, A. Scott, H. Zibara, The effect of supplementary cementitious materials on chloride binding in hardened cement paste, Cem. Concr. Res. 42 (1) (2012) 1-7.

[14] R.K. Dhir, M.A.K. El-Mohr, T.D. Dyer, Chloride binding in GGBS concrete, Cem. Concr. Res. 26 (12) (1996) 1767-1773.

[15] J. Csizmadia, G. Balázs, F.D. Tamás, Chloride ion binding capacity of aluminoferrites, Cem. Concr. Res. 31 (4) (2001) 577-588.

[16] M.V.A. Florea, H.J.H. Brouwers, Modelling of chloride binding related to hydration products in slag-blended cements, Constr. Build. Mater. 64 (2014) 421-430.

[17] B. Lothenbach, K. Scrivener, R.D. Hooton, Supplementary cementitious materials, Cem. Concr. Res. 41 (12) (2011) 1244-1256.

[18] P.D. Tennis, H.M. Jennings, A model for two types of calcium silicate hydrate in the microstructure of Portland cement pastes, Cem. Concr. Res. 30 (6) (2000) 855-863.

[19] H.J.H. Brouwers, The work of Powers and Brownyard revisited: Part 1, Cem. Concr. Res. 34 (9) (2004) 1697-1716.

[20] T.S. Zhang, Q.J. Yu, J.X. Wei, P.P. Zhang, Effects of size fraction on composition and fundamental properties of Portland cement, Constr. Build. Mater. 25 (7) (2011) 3038-3043.

[21] T.S. Zhang, Q.J. Yu, J.X. Wei, P.P. Zhang, S. Li, Effect of size fraction of ground granulated blast furnace slag on its strength contribution and hydraulic activity, Adv. Sci. Lett. 4 (3) (2011) 12861291.

[22] B. Lothenbach, F. Winnefeld, C. Alder, E. Wieland, P. Lunk, Effect of temperature on the pore solution, microstructure and hydration products of Portland cement pastes, Cem. Concr. Res. 37 (4) 
(2007) 483-491.

[23] M.H. Shehata, M.D.A. Thomas, R.F. Bleszynski, The effects of fly ash composition on the chemistry of pore solution in hydrated cement pastes, Cem. Concr. Res. 29 (12) (1999) 1915-1920.

[24] ASTM C1702-09A, Standard test method for measurement of heat of hydration of hydraulic cementitious materials using isothermal conduction calorimetry, ASTM Int. West Conshohocken, PA, 2009.

[25] ASTM C1608, Standard test method for chemical shrinkage of hydraulic cement paste, ASTM Int. West Conshohocken, PA, 2007.

[26] T.S. Zhang, P. Gao, Q.J. Yu, J.X. Wei, Measurement of chemical shrinkage of cement paste: Comparison study of ASTM C 1608 and an improved method, Constr. Build. Mater. 48 (2013) $662-$ 669.

[27] ASTM C1218/C1218M, Standard test method for water-soluble chloride in mortar and concrete, ASTM Int. West Conshohocken, PA, 2017.

[28] S. Brunauer, P.H. Emmett, E. Teller, Adsorption of gases in multimolecular layers, J. Am. Ceram. Soc. 60 (2) (1938) 309-319.

[29] M. Balonis, B. Lothenbach, G. Le Saout, F.P. Glasser, Impact of chloride on the mineralogy of hydrated Potland cement systems, Cem. Concr. Res. 40 (7) (2010) 1009-1022.

[30] U.A. Birnin-Yauri, F.P. Glasser, Friedel's salt, $\mathrm{Ca}_{2} \mathrm{Al}(\mathrm{OH})_{6}(\mathrm{Cl}, \mathrm{OH}) \cdot 2 \mathrm{H}_{2} \mathrm{O}$ : its solid solutions and their role in chloride binding, Cem. Concr. Res. 28 (12) (1998) 1713-1723.

[31] Z. Shi, M.R. Geiker, B. Lothenbach, K. De Weerdt, Friedel's salt profiles from thermogravimetric analysis and thermodynamic modelling of Portland cement-based mortars exposed to sodium chloride solution, Cem. Concr. Compos. 78 (2017) 73-83.

[32] T.S. Zhang, Q.J. Yu, J.X. Wei, Study on optimization of hydration process of blended cement, J. Therm. Anal. Calorim. 107 (2) (2012) 489-498.

[33] Y. Elakneswara, T. Nawa, K. Kurumisawa, Electrokinetic potential of hydrated cement in relation to adsorption of chlorides, Cem. Concr. Res. 39 (4) (2009) 340-344.

[34] Y. Elakneswaran, A. Iwasa, T. Nawa, T. Sato, K. Kurumisawa, Ion-cement hydrate interactions govern multi-ionic transport model for cementitious materials, Cem. Concr. Res. 40 (12) (2010) $1756-1765$

[35] F. Martini, M. Tonelli, M. Geppi, F. Ridi, S. Borsacchi, L. Calucci, Hydration of $\mathrm{MgO} / \mathrm{SiO}_{2}$ and Portland cement mixtures: A structural investigation of the hydrated phases by means of X-ray diffraction and solid state NMR spectroscopy, Cem. Concr. Res. 102 (2017) 60-67.

[36] F. Brunet, T. Charpentier, C.N. Chao, H. Peycelon, Characterization by solid-state NMR and 
selective dissolution techniques of anhydrous and hydrated CEM V cement pastes, Cem. Concr. Res. 40 (2) (2010) 208-219.

[37] J. Skibsted, H.J. Jakobsen, Characterization of the calcium silicate and aluminate phases in anhydrous and hydrated Portland cements by ${ }^{27} \mathrm{Al}$ and ${ }^{29} \mathrm{Si}$ MAS NMR spectroscopy, NMR Spectroscopy of Cement-Based Materials, Springer, 1998.

[38] M. Adachi-Pagano, C. Forano, J.P. Besse, Delamination of layered double hydroxides by use of surfactants, Chem. Commun. (1) (2000) 91-92.

[39] Y. Elakneswaran, T. Nawa, The importance of C-A-S-H surface chemistry on chloride resistance of slag-blended cement, International Conference on Advances in Construction Materials and Systems, 2017.

[40] M.V.A. Florea, H.J.H. Brouwers, Chloride binding related to hydration products Part I: Ordinary Portland cement, Cem. Concr. Res. 42 (2) (2012) 282-290.

[41] H. Viallis-Terrisse, A. Nonat, J.C. Petit, Zeta-potential study of calcium silicate hydrates interacting with alkaline cations, J. Colloid Interface Sci. 244 (1) (2001) 58-65. 